See Article page e337.

\section{Commentary: Early success of mitochondrial-based biologic therapy for experimental aortic surgery-related spinal cord injury}

\author{
Hilary P. Grocott, MD, FRCPC, FASE
}

Despite significant advances in the treatment of thoracoabdominal aortic aneurysm (TAA) and other acute aortic syndromes, the risk of ischemic spinal cord injury (SCI) is significant and remains a relatively common and devastating complication after both open surgery and endovascular surgery. ${ }^{1,2}$ Years of research have enhanced our understanding of the complex pathophysiology surrounding this problem, including an evolved understanding of the importance of collateral circulation networks. ${ }^{3}$ Although there was initial optimism that the transition from open surgery to endovascular approaches (ie, thoracic endovascular aortic repair) would see the end to SCI (or at least a significant reduction), this has not been the case. ${ }^{4}$ Somewhat paradoxically, the total numbers of patients with SCI have likely increased as these lesser invasive approaches to thoracoabdominal aortic aneurysm have allowed for expansion of procedures to an increasingly complex patient cohort with significant comorbidities and advanced age. In short, this problem is not going away any time soon.

No specific treatment modalities for SCI are currently available, and even cerebrospinal fluid drainage itself is generally only a modestly effective preventive measure. ${ }^{5}$ This is not dissimilar to the setting of stroke, in which no specific pharmacologic therapeutic agents exists; that is, thrombolytics reduce thromboembolic-related cerebral ischemia but do not directly treat it per se once it has occurred. However, research continues, and in this issue of the Journal, Fang and colleagues ${ }^{6}$ outline an important

\footnotetext{
From the Department of Anesthesiology, Perioperative and Pain Medicine, University of Manitoba, Winnipeg, Manitoba, Canada.

Disclosures: Author has nothing to disclose with regard to commercial support.

Received for publication Nov 14, 2019; revisions received Nov 14, 2019; accepted for publication Nov 14, 2019; available ahead of print Dec 7, 2019.

Address for reprints Hilary P. Grocott, MD, FRCPC, FASE, University of Manitoba, CR3008, 369 Tache Ave, Winnipeg, Manitoba, Canada R2H 2A6 (E-mail: hgrocott@sbgh.mb.ca).

J Thorac Cardiovasc Surg 2021;161:e349-50

$0022-5223 / \$ 36.00$

Copyright (c) 2019 by The American Association for Thoracic Surgery

https://doi.org/10.1016/j.jtcvs.2019.11.064
}

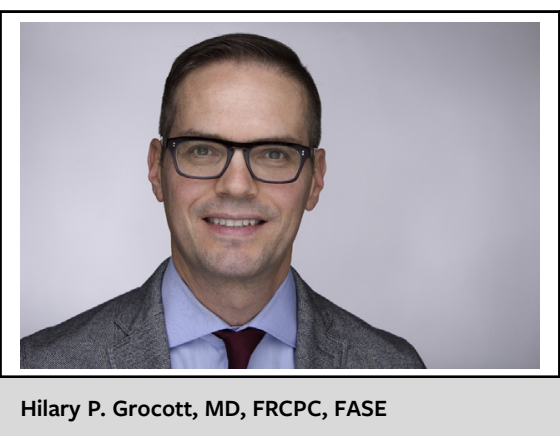

CENTRAL MESSAGE

An experimental model of spinal cord ischemia was used to study the potential beneficial effect of exogenous mitochondrial transplantation.

novel therapeutic pathway that highlights the importance of mitochondrial dysfunction in the setting of SCI. ${ }^{7}$ In their rat model of aortic cross-clamping, they show that intravenous injection of endogenously harvested mitochondria reduced SCI and improved 7-day hind limb motor function.

Mitochondrial dysfunction is recognized as an important mechanism in secondary injury occurring in the setting of ischemia-reperfusion with opening of the mitochondrial transition pore leading to significant inflammatory-related injury. ${ }^{8}$ Restoring normal mitochondrial function via "transplantation" thus represents a potential important biological therapeutic and has shown benefits in a range of ischemia-reperfusion injury models. ${ }^{7}$ In the study of Fang and colleagues, mitochondrial injection reduced the neuroinflammatory response and other mitochondrial and endoplasmic reticulum stresses, leading to reduced neuronal apoptosis and chromatolysis.

Despite these encouraging results, any advance such as this must be considered with caution. This is but one study in one animal model, and arguably a period of years, if not longer, is needed to fully understand its potential clinical application. Significant questions remain. For example, although the presence of these organelle transplants in the spinal cord were shown using an in vivo bioluminescent imaging technique, the mechanism by which these mitochondria "homed in" on the injured spinal cord itself was not well elucidated. In addition, considerable work is needed to better understand the optimal timing and dose response 
of these mitochondrial injections. That said, this is an important potential therapeutic pathway that warrants carefully considered future research.

\section{References}

1. Acher C, Wynn M. Outcomes in open repair of the thoracic and thoracoabdominal aorta. J Vasc Surg. 2010;52(4 Suppl):3S-9S.

2. Corvera J, Copeland H, Blitzer D, Hicks A, Manghelli J, Hess P, et al. Open repair of chronic thoracic and thoracoabdominal aortic dissection using deep hypothermia and circulatory arrest. J Thorac Cardiovasc Surg. 2017;154:389-95.

3. Awad H, Ramadan ME, El Sayed HF, Tolpin DA, Tili E, Collard CD. Spinal cord injury after thoracic endovascular aortic aneurysm repair. Can J Anaesth. 2017;64: 1218-35.
4. Frederick JR, Woo YJ. Thoracoabdominal aortic aneurysm. Ann Cardiothorac Surg. 2012;1:277-85.

5. Fedorow CA, Moon MC, Mutch WA, Grocott HP. Lumbar cerebrospinal fluid drainage for thoracoabdominal aortic surgery: rationale and practical considerations for management. Anesth Analg. 2010;111: 46-58.

6. Fang SY, Roan JN, Lee JS, Chiu MH, Lin MW, Liu CC, et al. Transplantation of viable mitochondria attenuates neurologic injury after spinal cord ischemia. $J$ Thorac Cardiovasc Surg. 2021;161:e337-47.

7. Scholpa NE, Schnellmann RG. Mitochondrial-based therapeutics for the treatment of spinal cord injury: mitochondrial biogenesis as a potential pharmacological target. J Pharmacol Exp Ther. 2017;363:303-13.

8. Sullivan PG, Krishnamurthy S, Patel SP, Pandya JD, Rabchevsky AG. Temporal characterization of mitochondrial bioenergetics after spinal cord injury. J Neurotrauma. 2007;24:991-9.
See Article page e337.

\section{Commentary: Mitochondria to the rescue?}

\author{
Nirvik Pal, MBBS, MD, and John Butterworth, MD
}

Precision medicine, machine learning, and artificial intelligence are the current buzz words of choice in medicine. To that list, we may soon add "organelle autotransfusion." In this edition of the Journal, Fang and colleagues ${ }^{1}$ describe a novel potential treatment for ischemia-reperfusion injury in the spinal cord. In rat experiments, the authors harvested and isolated mitochondria, injected them intravenously during spinal cord ischemia, imaged the distribution of the mitochondria, and assessed motor function after restoration of circulation. The authors report spectacularly positive results. The isolation and harvesting procedures, requiring only approximately 30 minutes, make this technique potentially applicable to surgical patients.

\footnotetext{
From the Department of Anesthesiology, Virginia Commonwealth University School of Medicine, Richmond, Va.

Disclosures: Authors have nothing to disclose with regard to commercial support.

Received for publication Nov 26, 2019; revisions received Nov 26, 2019; accepted for publication Nov 26, 2019; available ahead of print Dec 14, 2019.

Address for reprints: John Butterworth, MD, Department of Anesthesiology, Virginia Commonwealth University School of Medicine, PO Box 980695, Richmond, VA 23298-0695 (E-mail: John.butterworth@vcuhealth.org).

J Thorac Cardiovasc Surg 2021;161:e350-1 0022-5223/ $\$ 36.00$

Copyright $₫ 2019$ Published by Elsevier Inc. on behalf of The American Association for Thoracic Surgery

https://doi.org/10.1016/j.jtcvs.2019.11.109
}

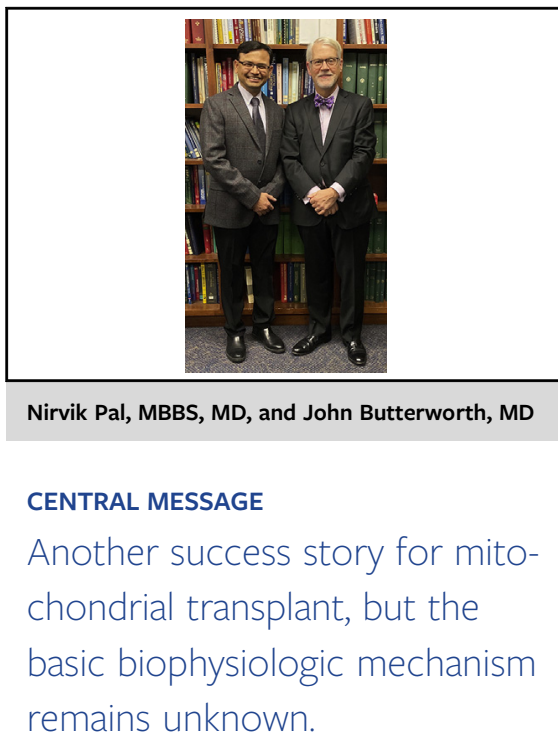

Previous investigators showed that mitochondrial transplantation ameliorates myocardial injury in animals ${ }^{2}$ and humans. ${ }^{3,4}$ How do the transplanted mitochondria detect the target tissue? How do they migrate across plasma membranes? If they do not cross plasma membranes, how can they augment intracellular energy production? The authors harvested mitochondria from one rat and administered them to another; should we anticipate that allogenic mitochondria would generate some sort of immunologic response? Potential therapeutic mechanisms for mitochondrial transplantation include supplementation of bioenergetic substrates and antioxidants, or upregulation of enzymes for oxidative phosphorylation. ${ }^{5}$ But in truth, we don't 